Case 3

A 72-year-old retired business man presented with renal colic, having passed calculi 8 and 6 years previously. A duodenal ulcer had been demonstrated radiologically 30 years before, since when he had regularly taken $7 \mathrm{~g}$ of calcium carbonate, $20 \mathrm{~g}$ of sodium bicarbonate and less than one half pint of milk per day for heartburn and indigestion.

Investigations revealed normal haemoglobin and plasma sodium, potassium, bicarbonate, alkaline phosphatase, calcium, phosphate, urate, proteins and parathyroid hormone. The blood urea was $8.7 \mathrm{mmol} / \mathrm{l}$ and creatinine clearance $58 \mathrm{ml} / \mathrm{min}$. Urinary calcium and phosphate excretion rates were normal on a ward diet without antacids.

An intravenous pyelogram showed calculi in both renal pelves and an obstructing mid-ureteric calculus, which subsequently passed spontaneously.

\section{Comments}

These patients had taken calcium carbonate and sodium bicarbonate regularly several times daily for 20 to 30 years. Excessive calcium ingestion produces hypercalciuria and renal calculi in susceptible individuals (Nordin, 1977). Case 1 closely resembled the acute form of the milk alkali syndrome (McMillan and Freeman, 1965).
Although these patients obtained their original prescriptions from their doctors, the antacid powders were subsequently supplied by pharmacists for 20-30 years, unknown to the patients' current general practitioners. These obsolete antacid mixtures are still causing clinical problems which could readily be prevented if such powders were no longer obtainable.

\section{Acknowledgments}

We thank Professor R. H. Girdwood and Mr J. W. Fowler for permission to report the patients under their care, and Dr L. F. Prescott for his helpful comments.

\section{References}

FoRdTRAN, J.S. (1968) Acid rebound. New England Journal of Medicine, 279, 900.

LeVant, J.A., Walsh, J.H. \& Isenberg, J.I. (1973) Stimulation of gastric secretion and gastrin release by single oral doses of calcium carbonate in man. New England Journal of Medicine, 289, 555.

McMillan, D.E. \& Freeman, R.B. (1965) The milk alkali syndrome: A study of the acute disorder with comments on the development of the chronic condition. Medicine, 44, 485 .

Nordin, B.E.C. (1977) Hypercalciuria. Clinical Science and Molecular Medicine, 52, 1.

Piper, D.W. \& FEnToN, B.H. (1964) An evaluation of antacids in vitro. Gut, $5,585$.

\title{
Myocardial ischaemia in migraine sufferers taking ergotamine
}

\author{
N. J. C. SNELL \\ M.B., M.R.C.P.
}

\author{
C. Russell-SMith \\ M.B., B.S.
}

H. L. CoYSH
M.B., D.C.H.

Department of Medicine, Battle Hospital, Reading 


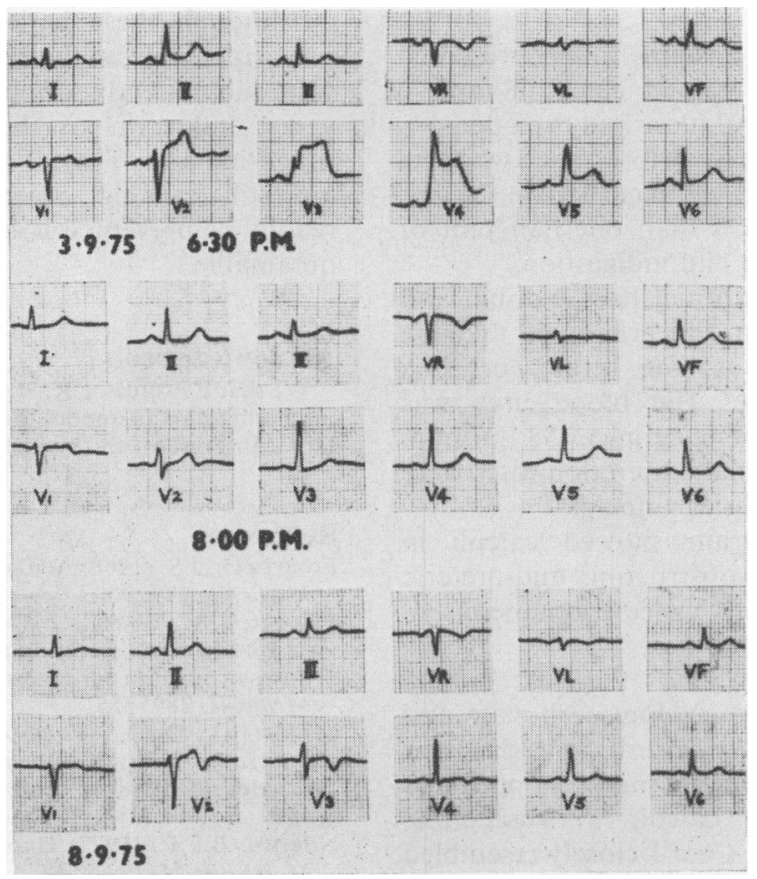

FIG. 1. Case 1. ECG report.

repolarization changes developed in the septal leads of his ECG. Serial estimations of serum creatine kinase, aspartate transaminase, and hydroxybutyrate dehydrogenase, on days $1,2,5$, and 7 after admission, were within normal limits. His further course was uneventful; he was advised to avoid medications containing ergotamine in the future. When reviewed as an out-patient at 4 months and 9 months after discharge he had remained symptom-free despite returning to vigorous work, and his ECG had returned to normal.

\section{Case 2}

A 40-year-old woman had suffered from classical migraine for 4 years; this was controlled by ergotamine (as Migril tablets) her total dose never exceeding $2 \mathrm{mg}$ in 1 week. On the afternoon of admission she felt a headache developing so took one tablet (containing $2 \mathrm{mg}$ ergotamine) and fell asleep for approximately $10 \mathrm{~min}$, being awakened by severe central chest pain radiating to the left arm. Her general practitioner was called and gave sublingual glyceryl trinitrate with some relief, followed by intravenous morphine. She was admitted to hospital. On arrival, physical examination was normal; her initial ECG was unremarkable (Fig. 2) but by the following morning $\mathrm{T}$ wave inversion had developed

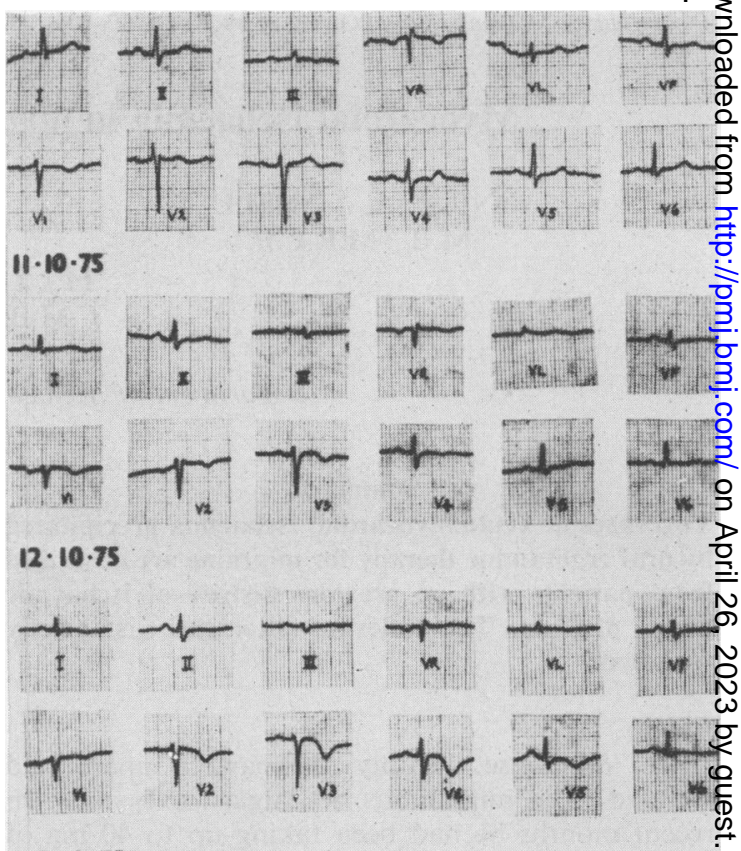

FIG. 2. Case 2. ECG report. 
in the anteroseptal leads, which persisted over the next 10 days. Cardiac enzyme estimations on days 1 and 4 were normal. She was advised to avoid ergotamine in future. At review 6 months after discharge her ECG had returned to normal, and she had suffered no further chest pain.

\section{Discussion}

Both these patients developed unequivocal angina following the use of ergotamine. The ECG changes in the first case correspond to those described in the Prinzmetal variety of angina, in which pain due to coronary artery spasm develops at rest, the ECG characteristically showing transient S-T segment elevation. Prinzmetal angina often occurs in subjects with anatomically normal coronary arteries, and attacks can be provoked by various pharmacological agents including methacholine (Endo et al., 1976) and ergometrine (Higgins et al., 1976); it has not previously been described after ergotamine administration. Leon-Sotomayor (1974) has described twelve patients with a syndrome characterized by migraine headaches, coronary artery spasm, and functional hypoglycaemia; it was noted that ergometrine improved the headache but worsened the chest pain. It may be that the first patient was predisposed to Prinzmetal angina and this was precipitated by his recently increased ergotamine intake.

Ergotamine has been used in the treatment of migraine since 1883; considering the number of patients regularly taking this potent vasoconstrictive drug, it is perhaps surprising that severe side effects are not reported more often; those described in the literature include ischaemia of the extremities (Felix and Carroll, 1970; Imrie, 1973), papillitis due to vasoconstriction around the optic nerve (Gupta and Strobos, 1972) and renal arterial spasm (Fedotin and Hartman, 1970). There have been several reports of myocardial ischaemia due to the use of ergotamine, for indications other than migraine, in patients with known heart disease (Labbé et al., 1929a; Lichtman, 1936; Scherf and Schlachman, 1948; McNerney and Leedham, 1950), and also in a case of thyrotoxicosis (Labbé, Justin-Besançon and Gouyen, 1929b). In a survey of the literature four cases of myocardial ischaemia occurring in previously healthy migraine sufferers have been found; in two of these angina occurred (Bailey Carter, 1940; Bernreiter, 1965), one developed a probable myocardial infarct (Fuchs and Blumenthal, 1950), and one a definite infarct (Goldfischer, 1960). A further complication of the use of ergotamine for migraine is that the drug itself may cause headache, and this may lead to an increase in dose by the patient, and the establishment of a vicious circle (Wainscott, Volans and Wilkinson, 1974). It should be emphasized that the recom- mended dosage (a maximum of $4 \mathrm{mg}$ ergotamine in 1 day, and $10 \mathrm{mg}$ in any 1 week) should never be exceeded even in healthy patients; it should be used with caution in cases of liver disease since it is metabolized in the liver; and its use is absolutely contraindicated in known cases of ischaemic heart disease or peripheral vascular insufficiency.

\section{Acknowledgments}

Our thanks are due to Dr K. A. K. North, Consultant Physician, Royal Berkshire Hospital, for permission to report his cases; and to Dr J. A. Bell, Consultant Cardiologist, Battle Hospital, for his advice.

\section{References}

Bailey Carter, J. (1940) Cardiac manifestations following ergotamine tartrate therapy for migraine. Journal of the American Medical Association, 114, 2298.

BERNREITER, M. (1965) Severe angina pectoris and electrocardiographic changes after Cafergot medication. Journal of the Kansas Medical Society, 66, 464.

Endo, M., Hirosawa, K., Kaneko, N., Hase, K., Inone, Y. \& Konno, S. (1976) Prinzmetal's variant angina; coronary arteriogram and left ventriculogram during angina attack induced by methacholine. New England Journal of Medicine, 294, 252.

Fedotin, M. \& Hartman, C. (1970) Ergotamine poisoning producing renal arterial spasm. New England Journal of Medicine, 283, 518.

Felix, R. \& Carroll, J. (1970) Upper limb ischaemia due to ergotamine tartrate. Practitioner, 205, 71.

Fuchs, M. \& Blumenthal, L. (1950) Use of ergot preparations in migraine. Journal of the American Medical Association, 143, 1462.

GoldFISCHER, J. (1960) Acute myocardial infarction secondary to ergot therapy. New England Journal of Medicine 262, 860.

GuPTA, D. \& STrobos, R. (1972) Bilateral papillitis associated with Cafergot therapy. Neurology. Minneapolis, 22, 793.

Higgins, C., Wexler, L., Silberman, J., Hayden, W., ANDERSon, W. \& Schroeder, J. (1976) Spontaneously and pharmacologically provoked coronary arterial spasm in Prinzmetal variant angina. Radiology, 119, 521.

IMRIE, C. (1973) Arterial spasm associated with oral ergotamine therapy. British Journal of Clinical Practice, 20, 457.

Labbe, M., Justin-Besançon, L., Boulin, R. \& Gouyen, J. (1929a) L'angine de poitrine ergotaminique. Presse Médicale, 37, 1069.

LabBé, M., Justin-Besançon, L. \& Gouyen, J. (1929b) Accidents consécutifs au traitement de la maladie de Basedow par le tartiate d'ergotamine. Bulletin et Mémoires de la Société Médicale des Hôpitaux de Paris, 53, 429.

LEON-SOTOMAYOR, L. (1974) Cardiac migraine-report of 12 cases. Angiology, 25, 161.

Lichtman, S. (1936) Clinical experience with ergotamine tartrate. Journal of the American Medical Association, 100, 148.

McNerney, J. \& Leedham, C. (1950) Acute coronary insufficiency pattern following intravenous ergotamine studies. American Heart Journal, 39, 629.

SCHERF, D. \& SChlaCHMAN, M. (1948) Electrocardiographic and clinical studies on the action of ergotamine tartrate and dihydroergotamine 45. American Journal of Medical Science, 216, 673.

WainscotT, G., Volans, G. \& Wilkinson, M. (1974) Ergotamine-induced headache, British Medical Journal, 2, 74. 